ISSN 0103-5150

Fisioter. Mov., Curitiba, v. 24, n. 2, p. 299-306, abr./jun. 2011 Licenciado sob uma Licença Creative Commons

\title{
Acessibilidade e crianças com paralisia cerebral: a visão do cuidador primário
}

\author{
Accessibility in children with cerebral palsy: primary caregiver view
}

\author{
Luciane Maria Fagundes Pereira ${ }^{[a]}$, Daniela Caribé ${ }^{[b]}$, Pedro Guimarães ${ }^{[c]}$, Daniela Matsuda ${ }^{[d]}$ \\ [a] Acadêmica de Fisioterapia, Faculdade Social, Salvador, BA - Brasil, e-mail: luka_ssa@yahoo.com.br \\ [b] Fisioterapeuta, Mestre em Desenvolvimento Humano e Responsabilidade Social / Fundação Visconde de Cairú, Salvador, \\ BA - Brasil, e-mail: danielacaribe@yahoo.com.br \\ [c] Doutor em Medicina pela Universidade Federal de São Paulo (UNIFESP) / Escola Paulista de Medicina e professor associado \\ I da FAMED/Universidade Federal da Bahia (UFBA), Salvador, BA - Brasil, e-mail: guimaraespedro@terra.com.br \\ [d] Doutora em Medicina pela Universidade de São Paulo (USP), São Paulo, SP - Brasil, e-mail: dmat@terra.com.br
}

\section{Resumo}

Introdução: A paralisia cerebral (PC) é uma disfunção predominantemente sensório-motora que envolve distúrbios do tônus muscular, postura e movimentos voluntários, ocasionada por lesões cerebrais não progressivas. Esta condição de saúde interfere de forma importante na interação da criança em contextos relevantes, que influencia a aquisição e o desempenho dos marcos motores básicos, bem como nas atividades da rotina diária. É por isso que a acessibilidade é uma questão fundamental na vida das crianças com PC e um direito de todas elas para construir valores individuais e sociais, os quais eliminem os obstáculos e possibilitem a comunicação com o mundo. Objetivo: Verificar as dificuldades de acessibilidade, sob a ótica dos cuidadores primários, encontradas no cotidiano das crianças com PC. Método: Trata-se de um estudo qualitativo, de estudo de caso. Foram selecionados três cuidadores primários de crianças com PC que concordaram em realizar a entrevista e assinaram o TCLE. Os dados foram transcritos e categorizados. Resultados e Discussão: Verificou-se que a escassez de informações sobre as potencialidades da criança com PC é comum na sociedade atual, o que contribui para existência de barreiras atitudinais, assim como para precariedade em acessibilidade geral destas pessoas. Considerações finais: Concluise que é necessária inclusão de programas educativos nas escolas e maior apoio voltado aos cuidadores 
primários nas clínicas de reabilitação e outras instituições especializadas, pois mesmo diante das dificuldades as mães encontram formas e condições de cuidar e lutar por estas crianças.

Palavras-chave: Paralisia cerebral. Acessibilidade. Deficiência.

\section{Abstract}

Introduction: Cerebral palsy (CP) is an abnormality of the motor control which predominantly involves trouble controlling of the muscles tone, posture and voluntary movements caused by damage to the brain. This health condition affects strongly the child interaction considering relevant and influential contexts in the acquisition and performance not about only basics movements, but also activities of daily routine as bath, feed, wear or move yourself. That is why the accessibility is a fundamental issue in the lives of children with CP and this is a right of all of them to build up individual and social values which will eliminate the obstacles and make possible the communication with the world. Objective: Check the difficulties of accessibility, from the perspective of primary caregivers, found daily in children with cerebral palsy. Method: This is a qualitative study, which will be used as a method of study of case. Were chose three primary caregivers of children with CP who agreed to give an interview and signed the TCLE. The data were transcribed and categorized. Results and discussion: Was verified a scarcity of information about the potentialities of children with PC so common in the actual society which contributes to the existence of attitudinal barriers as well as to the precariousness in general accessibility for these people. Conclusion: As a conclusion, will be necessary the inclusion of educative programs in the schools and also increase the support to the primary caregivers in rehabilitation clinics and in others specialized institutions, because even in front of all difficulties mothers always find some way to take care and fight for these children.

Keywords: Cerebral palsy. Accessibility. Disabilities.

\section{Introdução}

A paralisia cerebral (PC) é uma disfunção predominantemente sensório-motora que envolve os distúrbios do tônus muscular, postura e movimentos voluntários, ocasionada por lesões cerebrais, geralmente associadas com hipóxia e/ou anóxia ocorrentes no período de maturação estrutural e funcional do cérebro (1-11). Em relação à incidência, observam-se índices de 1,5 a 2,5 para cada mil nascidos vivos nos países desenvolvidos, e de sete para cada mil nascidos vivos em países em desenvolvimento. No Brasil, os dados estimam cerca de $30 \mathrm{mil} \mathrm{a} 40 \mathrm{mil}$ casos novos por ano (2).

$\mathrm{O}$ indivíduo com PC herda um determinado ritmo de evolução do sistema nervoso, mas junto com as potencialidades de sua atividade motora, instintivo-afetiva e intelectual, herda também a capacidade de adaptação, ou seja, a plasticidade cerebral, que é a base da aprendizagem (3). Portanto, a criança com essa condição de saúde apresenta alterações motoras e sensoriais, em diferentes graus, e com seu desenvolvimento neuropsicomotor mais lento.
Desta forma, essa criança com alterações sensóriomotoras irá construir e organizar seu universo de acordo com suas possibilidades e as condições proporcionadas pelo seu meio (1).

As consequências clínicas e funcionais dependem da extensão da área topográfica acometida no cérebro, do grau da lesão e dos fatores ambientais e de tarefas que envolvem o desenvolvimento do indivíduo. Com isso, a criança com PC geralmente não possui o controle completo dos movimentos, o que a leva ter dificuldades motoras e desordem na coordenação, que podem afetar desde seu desenvolvimento físico até sua fonação. Muitas vezes criam-se mitos em relação à criança com paralisia cerebral, que geram imagens distorcidas e preconceituosas sobre sua capacidade cognitiva e potencialidades para uma vida independente e autônoma (4-6).

A acessibilidade torna-se relevante por mostrar à sociedade que é de fundamental importância na vida dessas crianças com PC, como na de todos os seres humanos, o direito de interagir com o meio e construir seus valores na sociedade. Esta garante o direito de exercer a cidadania e o direito de ir e vir, 
que elimina as barreiras de transporte e comunicação dessas crianças com o mundo $(7,12)$.

Portanto, a falta de acessibilidade a determinados locais e serviços leva as pessoas com deficiência a se sentirem à margem da sociedade, o que gera, muitas vezes, perturbações de estima e comportamento, o que contribui ainda mais para a segregação social $(13,14)$ Isso faz com que muitas crianças com PC sejam isoladas na sociedade, sem estímulos e oportunidades, o que dificulta seu desenvolvimento biopsicossocial, e acaba por desvalorizar as suas potencialidades. A sociedade é que está excluída da oportunidade da convivência, do compartilhamento e do crescimento coletivo, se referindo à criança com paralisia cerebral e sua família, que, geralmente, vivem à margem do sistema sócio-econômicocultural do Brasil (4).

A acessibilidade não funciona somente para as crianças com paralisia cerebral, que possuem uma deficiência permanente, consequente de uma condição de saúde pregressa, mas também para as pessoas que apresentam uma deficiência transitória, como uma torção de articulação tíbio-társica. Alguns autores definem acessibilidade como o processo de eliminação de barreiras, não só físicas, mas do campo de informações, das atitudes. $\mathrm{O}$ aspecto atitudinal da sociedade pode fazer com que as pessoas com deficiência sintam-se integradas com o meio, sujeitos participantes de uma realidade, e, portanto, as atitudes podem ser facilitadores do processo de inclusão da criança com PC ou se tornar uma barreira que exclui estes cidadãos do direito de participação na sociedade. Outra definição apresenta a acessibilidade como uma condição que cumpre um ambiente, espaço ou objeto para ser utilizado por todas as pessoas $(7,15-17)$.

Para melhorar o conhecimento sobre acessibilidade na sociedade devem-se implantar políticas destinadas a aumentar o acesso, favorecendo melhor qualidade de vida para as pessoas com deficiência, pois a acessibilidade não envolve somente os aspectos urbanísticos, arquitetônicos, de informação e de comunicação, mas também os aspectos atitudinais, quando todos os membros da sociedade observam, compreendem e constroem o processo de acessibilidade $(6,7)$.

A realização deste estudo baseia-se em curiosidade técnico-científica, enquanto estudante de Fisioterapia, diante da condição de saúde paralisia cerebral, já que esta se apresenta em alta incidência no Brasil e, ainda assim, desprovida de informações adequadas sobre a sua realidade e impacto social. Esta pesquisa com base de referências bibliográficas tem como objetivo verificar as dificuldades de acessibilidade, sob a ótica dos cuidadores primários, encontradas no cotidiano das crianças com Paralisia Cerebral.

\section{Materiais e métodos}

\section{Amostra}

Este estudo contou com a participação de três cuidadores primários das crianças com PC, para coleta de dados, tendo como critério de inclusão: cuidadores de crianças com diagnóstico confirmado de PC e cuidadores de crianças em idade escolar ( $>4$ anos de idade). Os critérios de exclusão foram: cuidadores de crianças com diagnóstico não fechado de PC; cuidadores de crianças de menores de 4 anos; cuidadores que não frequentam o Centro de Reabilitação com a criança com PC; cuidadores que rejeitam participar da pesquisa. Os cuidadores primários foram entrevistados por meio de uma entrevista semiestruturada, a qual apresentou categorias/perguntas baseadas na Lei n. 10.098, de 19 de dezembro de 2000, a qual estabelece normas gerais e critérios básicos para promoção de acessibilidade das pessoas portadoras de deficiência ou com mobilidade reduzida e dá outras providências, e a Associação Brasileira de Normas Técnicas (ABNT) NBR 9050 (18), além de outras referências utilizadas na pesquisa bibliográfica do presente estudo. Todos os participantes assinaram o TCLE. 0 projeto foi aprovado pelo comitê de ética sob o protocolo n. 1.160.

\section{Procedimentos}

As entrevistas foram realizadas em local reservado, individualmente, foram gravadas num $\mathrm{mp} 3$ player e transcritas para permitir melhor análise dos dados. Nas perguntas da entrevista semiestruturada constaram: tipo de locomoção da criança fora de casa/ meio de transporte mais utilizado/ frequência de saída durante a semana / acesso à sua moradia (presença de escadas, ladeiras, tipo e/ ou qualidade de piso/passeio público que se locomove pelas ruas / presença de elevadores/presença 
de rampas e barras para acessibilidade nos locais externos / atitudes das pessoas dentro e fora de casa frente à deficiência/ aceitação da criança pela escola regular.

\section{Análise de dados}

Foi utilizada a análise descritiva dos dados. Para tanto, as entrevistas já transcritas foram lidas cuidadosamente. Posteriormente, as informações obtidas foram dispostas em série para criação de categorias de análise, com intenção de classificar elementos comuns. Assim como foi tabulada a frequência de eventos diferentes e construído o banco de dados para realização da descrição dos resultados.

\section{Resultados e discussão}

Os informantes chave da pesquisa foram três cuidadores primários de crianças com diagnóstico de paralisia cerebral com idades de 6, 8 e 10 anos. Todas as entrevistadas são mães biológicas. As mães dessas crianças são as principais figuras que intermediarão o desenvolvimento neuropsicomotor de seus filhos, a minimização de efeitos secundários consequentes à deficiência e a inclusão de seus filhos no meio familiar e social. A preocupação principal relatada pelas mães está relacionada às incertezas que envolvem o futuro de seus filhos, seu desenvolvimento, sua situação de dependência e sua inserção na sociedade (19).

Em relação ao questionamento:

Sai de casa quantas vezes por semana: todas as entrevistadas relataram mais de quatro vezes.

Locais que mais frequenta durante a semana: todas foram unânimes em: praia, praça, visita a parentes.

Locais que mais frequenta durante o fim de semana: os mesmos lugares mencionados no item anterior; o mais comum foi passeio para praia.

Meio de transporte mais utilizado: todas responderam a opção Ônibus coletivo.

Barreiras encontradas no dia a dia: no fim do século XX houve a compreensão de um importante período de mudanças da visão preconceituosa e de exclusão social sobre os deficientes, em virtude dos movimentos sociais criados pelos próprios indivíduos com deficência (20). As crianças maiores teriam maior dificuldade para se locomover em virtude da ação de alguns motoristas que não param próximo ao ponto ou ao passeio, aumentando o grau de dificuldade. Foi constatado que os períodos de chuva elevam as ausências dessas crianças nos locais de tratamento $(7,21)$. No estudo, a grande maioria relata que sofrem mais com o preconceito e dificuldade de acesso no transporte: "O preconceito das pessoas em relação ao meu filho, as pessoas olham torto para ele [...]" (Cuidadora 1). A respeito do acesso de transporte, afirma a Cuidadora 2: "Pegar ônibus, com cadeira de rodas, é complicado. No meu bairro só tem um ônibus adaptado, passa 6 horas, chega aqui 8 horas e só passa de novo 14h horas". A Cuidadora 3 , sobre o acesso, diz: "[...] o acesso as ruas que são horríveis [...]".

Barreiras arquitetônicas: urbanísticas, na edificação e nos transportes: as dificuldades ao acesso pelas barreiras físicas são salutares, pois contribuem para o repensar de práticas e proposição de ações, o que pode favorecer a promoção de saúde e qualidade de vida destes indivíduos, bem como a convivência em grupos socialmente produtivos. A reflexão e o despertar da consciência perante as potencialidades das pessoas com deficiência tornam possível a transformação de atitudes, as quais interferirão nas relações interpessoais e nos comportamentos das pessoas (13). As barreiras arquitetônicas normalmente encontradas são: ausência de pisos adequados, degraus, rampas, dimensão de portas, corrimãos, banheiros e transporte urbano. A acessibilidade do lazer para essas pessoas geralmente é difícil por causa das inúmeras barreiras arquitetônicas que rodeiam esses ambientes (20). Barreiras arquitetônicas têm sido definidas como obstáculos construídos no meio urbano ou nos edifícios, que impedem ou dificultam a livre circulação das pessoas que sofrem de alguma incapacidade transitória ou permanente (13). As cuidadoras, na sua grande maioria, demonstram indignação: "Os carros que param todos os passeios, que não dá para gente passar, a gente têm que passar pelos buracos, ladeira, muito quebra-mola [...]" (Cuidadora 3).

As calçadas brasileiras são estreitas, esburacadas, barulhentas, sem sombra, sem verde e cheias de barreiras como lixeiras, telefone público e pontos de ônibus mal colocados, carros estacionados, degraus, etc. Quando não há uma política de mobilidade urbana eficiente, cada pessoa busca uma solução, o que gera, entre outros problemas, o aumento do tráfego 
de veículos, a utilização do automóvel como meio de transporte individual e o impacto ao meio ambiente (21). "A maior dificuldade é o passeio, pois não tem rampa, o passeio é fino e esburacado, na lapa não tem uma rampa. Dentro de edifício, mercado não tem rampa [...]" (Cuidadora 2). A construção da cidadania da pessoa com deficiência é uma batalha cotidiana; o acesso aos direitos civis, políticos, sociais e coletivos, ao direito à saúde, educação, trabalho, cultura, lazer, é um agravamento das dificuldades dos outros cidadãos (22). Esta entrevistada evidencia um desgaste físico: "[...] É difícil, porque não encontramos o lugar adequado e adaptado. É complicado quando saio com ele, chego em casa cansada, ainda trabalho, é um desgaste físico muito grande [...]" (Cuidadora 1).

Utilização de transporte com acessibilidade atitudinal: no dilema da qualidade dos transportes enfocando o cidadão e o veículo, deve-se garantir a resolução da dicotomia que existe dentro das cidades, oferecer condições para os cidadãos realizarem deslocamentos individuais de forma segura e dar condições para que o trânsito urbano seja o mais acessível possível e tenha boas condições de mobilidade (23). Por sua vez, essa luta contagia a sociedade como um todo que busca alternativas que minimizem preconceitos e atitudes discriminatórias e que potencializem a equiparação de oportunidades, em especial quando se trata da participação nos serviços sociais. A educação, assim, é vista como carro-chefe que facilita ou não a entrada das pessoas nas relações sociais. Diante disto, ratificase a importância de despertar a consciência de cada cidadão a respeito de acessibilidade, barreiras e facilitadores, bem como das potencialidades das pessoas com deficiência física (22). As entrevistadas relataram um descaso ou falta de compromisso por parte dos motoristas, em especial, do ônibus adaptado, configurando um preconceito por parte deles:

\section{[...] Eu coloco ele no meu colo quando o ônibus} está cheio. As pessoas batem na perna dele, aí eu olho assim e desculpo, entendeu? Mas como tem adaptação, porque cadeira ele tem para ficar, mas não tem ônibus. No bairro tem dois ou três ônibus, mas tem horário, $e$ quando sai 6 horas da manhã, o ônibus só passa 8 [...] Aí não adianta porque tem o horário da fisioterapia [...]" (Cuidadora 1).
A Cuidadora 3 aponta: "[...] o transporte de elevador é mais apropriado para deficiente, mas eles acham que têm que passar direto porque aquele processo do elevador demora. Aí ficam xingando, ficam reclamando, ficam dando piadinhas [...] pessoal muito incompreensivo". Esta entrevistada evidencia em relação ao descaso por parte do motorista: "[...] o motorista vira a cara, não para o ônibus" (Cuidadora 2).

Dificuldades nas barreiras nas comunicações: a troca de olhares, os encontros e os contatos humanos exercem uma influência importante tanto na maneira como as pessoas são percebidas, quanto na maneira como percebem o ambiente social e urbano (24). Na pesquisa realizada todas as mães relataram o preconceito das pessoas:

A sociedade passa. Na frente de TV, rádio. A barreira é sempre querer colocar a pessoa com paralisia cerebral como coitadinho, eu tenho horror. Coitadinho por quê? Não eu não gosto. [...] $A$ diferença é que a pessoa não pode andar, mas pode ir na cadeira de rodas, pode participar, pode ir de muleta... Se for fazer uma prova e não passar, repete como qualquer outra pessoa [...] (Cuidadora 1).

A Cuidadora 2 afirma: "A única dificuldade, quando a pessoa não critica, ela chega e diz que ele é bonitinho. 'Você usava droga? Tentou tirar?' Ou então: 'bonitinho, coitadinho'. Isso temos que conviver".

Ah, tem muita gente que é muito nojenta. $O$ menino não pode fazer zoada que ficam fazendo cara feia. Ele tem mania de colocar a mão na boca e o pessoal se afasta com nojo [...] o pessoal tem muito preconceito ainda com os deficientes, quanto mais o deficiente que baba, que saliva direto, aí que o pessoal fica com nojo. A gente vê mesmo a cara que o pessoal faz (Cuidadora 3).

Processo de inclusão escolar

A escola inclusiva deve desenvolver sua pedagogia centrada na criança e deve ser capaz de educar a todas, a fim de modificar atitudes discriminatórias, em busca de uma comunidade acolhedora e 
inclusiva, na qual haja aceitação das diferenças e reciprocidade no relacionamento $(25,26)$. Apesar da garantia do acesso à escola pública, muitos alunos são reprovados e abandonam os estudos. Entre os fatores responsáveis por essa situação, estudos e pesquisas têm apontado a baixa qualidade do ensino e a inadequação da escola destinada aos jovens das camadas populares que a frequentam majoritariamente e, mais recentemente, os jovens com deficiência $(27,28)$. Para incentivar o desenvolvimento adequado de habilidades e competências do indivíduo com deficiência, como é ratificado pelas leis da educação inclusiva no Brasil, e para que esse exerça plenamente seu papel na sociedade e atenda aos seus próprios anseios e das partes interessadas, sobretudo de famílias com crianças com deficiências, tornam-se urgentes os apelos fortes para que tanto as gestões públicas quanto a sociedade civil organizada facilitem este processo (29). A preocupação principal relatada pelas mães está relacionada às incertezas que envolvem o futuro de seus filhos, seu desenvolvimento, sua situação de dependência e sua inserção na sociedade. A maneira encontrada, no relato das mães, para fazer frente a essas preocupações é o investimento na reabilitação da criança, sendo esse, por outro lado, diretamente influenciado pelas expectativas maternas (24). Neste estudo, as entrevistadas relataram ter dificuldades em encontrar vagas nas escolas regulares, mas algumas conseguiram na "instituição X" e "instituição Y", e o processo nas escolas destas instituições foi tranquilo.

Só frequenta escola daqui. Lá onde eu moro ninguém quer pegar porque ele usa fralda, ele fica salivando, aí o pessoal diz que não tem estrutura para o tipo de criança como ele. Ele já tem 6 anos aqui, frequenta escola da [instituição Y], mas do governo não. Não tive dificuldade nesta instituição não. Agora em escola fora já tive muito impacto, porque ele não anda, e eles só queriam criança que andasse (Cuidadora 3).

O indivíduo com necessidades educativas especiais, quando estimulado, encorajado e aceito no âmbito social em que participa, certamente consegue atingir resultados progressivos durante o processo ensino-aprendizagem $(30,31)$. Uma das mães relata: "No começo eu não queria, mas ele estava participando de um projeto no [instituto X]. Eu levava ele todo sábado, a professora se interessava, ganhava flores. Foi um período de evolução" (Cuidadora 2).

\section{Considerações finais}

0 presente estudo demonstra a falta de informação da sociedade em relação à PC. As mães, mesmo não tendo um grau de informações necessárias sobre esta condição de saúde, sentem-se responsáveis por assumir um papel mais ativo na reabilitação e na vida do filho com PC.

Em relação à acessibilidade, foi constatado no presente estudo que as barreiras arquitetônicas, urbanísticas e de transporte são rigorosamente significativas; com isso, os cuidadores primários das crianças com PC, enfrentam dificuldades extremas de locomoção em seus cotidianos.

Mas o principal aspecto que todas as mães relataram foi a questão da acessibilidade atitudinal por parte dos motoristas de ônibus, que não são educados e treinados de maneira adequada para atender à população, principalmente aos indivíduos deficientes. Assim, torna-se necessário oferecer melhor orientação aos motoristas de transporte coletivo, tendo em vista a capacitação adequada. Outra questão que foi relatada pelas entrevistadas foi o preconceito da sociedade perante as crianças com PC, incluindo a dificuldade de encontrar vagas nas escolas.

Torna-se necessária a inclusão de programas educativos nas escolas e maior apoio voltado aos cuidadores primários nas clínicas de reabilitação e outras instituições especializadas, pois mesmo diante das dificuldades as mães encontram formas e condições de cuidar e lutar por essas crianças. Sugere-se implantar políticas destinadas à acessibilidade, para os indivíduos adquirirem conhecimento sobre essa condição de saúde e para que possam oportunizar melhor qualidade de vida para as pessoas com deficiência e incluí-las na sociedade, pois assim todos os membros, tendo este conhecimento e informações adequadas, irão observar, compreender e construir um processo de acessibilidade, como uma responsabilidade de todos. É válido ressaltar a necessidade de mais estudos sobre esta temática. 


\section{Referências}

1. Guimarães P. Caminhos e conquistas na paralisia cerebral: uma ação interdisciplinar pela vida. Núcleo de Atendimento à Criança com Paralisia Cerebral. Salvador: NACPC; 2005.

2. Mancini MC, Fiúza PM, Rebelo JM, Magalhães LC, Coelho ZAC, Paixão ML, et al. Comparação do desempenho de atividades funcionais em crianças com desenvolvimento normal e crianças com paralisia cerebral. Arq Neuropsiquiatr. 2002;60(2-B): 446-52.

3. Rotta NT. Paralisia cerebral, novas perspectivas terapêuticas. J Pediatr. 2002;78(1):48-54.

4. Sonza AP, Santarosa LMC. Ambientes digitais virtuais: acessibilidade aos deficientes visuais. In: 1o Ciclo de Palestras sobre Novas Tecnologias na Educação CINTED-UFRGS; 2003; Porto Alegre. Porto Alegre. CINTED-UFRGS Novas tecnologias em educação; 2003. p. 1-11.

5. Mancini MC, Alves ACM, Schaper C, Figueiredo EM, Sampaio RF, Coelho ZAC, et al. Gravidade da paralisia cerebral e desempenho funcional. Rev Bras Fisioter. 2004;8(3):253-60.

6. Calgano NC, Pinto TPS, Vaz DV, Mancini MC, Sampaio RF. Análise dos efeitos da utilização da tala seriada em crianças portadoras de paralisia cerebral: uma revisão sistemática da literatura. Rev Bras Saúde Matern Infant. 2006;6(1):11-22.

7. Mazzoni AA, Torres EF, Oliveira RDE, Ely VHMB, Alves JBM. Aspectos que interferem na construção da acessibilidade em bibliotecas universitárias. Ci Inf. 2001;30(2):29-34.

8. Pinho DMCA, Lima IMSO. Salvador: cidade-mãe para crianças com paralisia cerebral? Uma análise sob a perspectiva do transporte público coletivo em Salvador [monografia]. Salvador: Faculdade Ruy Barbosa; 2007.

9. Guerzoni VPD, Barbosa AP, Borges ACC, Chagas PSC, Gontijo APB, Mancini MC. Análise das intervenções de terapia ocupacional no desempenho das atividades de vida diária em crianças com paralisia cerebral: uma revisão sistemática da literatura. Rev Bras Saúde Matern Infant. 2008; 8(1):17-25.
10. Cury VCR, Mancini MC, Melo AP, Fonseca ST, Sampaio RF, Tirado MGA. Efeitos do uso de órtese na mobilidade funcional de crianças com Paralisia Cerebral. Rev Bras Fisioter. 2006;10(1):67-74.

11. Morimoto MM, Sá CSC, Durigon OFS. Efeitos da intervenção facilitatória na aquisição de habilidades funcionais em crianças com paralisia cerebral. Rev Neurociênc. 2004;12(1):1-11.

12. Oliveira MFS, Silva MBM, Frota MA, Pinto JMS, Frota LMCP, Sá FE. Qualidade de vida do cuidador de crianças com paralisia cerebral. RBPS. 2008;21(4): 275-80.

13. Arelhano MV, Funes GPFM. A pessoa portadora de deficiência e o direito de locomoção: o direito a um ambiente acessível [acesso 26 maio 2010]. Disponível em: http://intertemas.unitoledo.br/revista/index.php/ ETIC/article/viewFile/1351/1290.

14. Lamônica DAC, Filho PA, Simonelli SBJ, Caetano VLSB, Regina MRR, Regiani DM. Acessibilidade em ambiente universitário: Identificação de barreiras arquitetônicas no campus da USP de Bauru. Rev Bras Ed Esp. 2008;14(2):177-88.

15. Caribé DM. Modelo interdisciplinar saúde e educação na paralisia cerebral do núcleo de atendimento à criança com paralisia cerebral [tese]. Salvador: Fundação Visconde de Cairú; 2009.

16. Pagliuca LMF, Aragão AEA, Almeida PC. Acessibilidade e deficiência física: identificação de barreiras arquitetônicas em áreas internas de hospitais de Sobral, Ceará. Rev Esc Enferm USP. 2007; 41(4):581-8.

17. Travassos C, Martins M. Uma revisão sobre os conceitos de acesso e utilização de serviços de saúde. Cad Saúde Pública. 2004;20(Sup 2):S190-S8.

18. Associação Brasileira de Normas Técnicas. NBR 9050, acessibilidade a edificações, mobiliário, espaços e equipamentos urbanos. [acesso 30 abr. 2009]. Disponível em: www.mpdft.gov.br/sicorde/NBR905031052004.pdf

19. Oliveira RFU, Silva RN, Junior NM. As condições de acessibilidade e adequação, para pacientes em cadeiras de rodas, em clínicas de fisioterapia na cidade de Goiânia. 2006 [acesso 26 maio 2010]. Disponível em: www.fisioweb.com.br. 
20. Lima RABC. Envolvimento materno no tratamento fisioterapêutico de crianças portadoras de deficiência: compreendendo dificuldades e facilitadores. [dissertação]. Belo Horizonte: Faculdade de Medicina da UFMG; 2006.

21. Liporoni AS, Machado A, Siqueira AP. Parâmetros para perícia em mobilidade urbana, acessibilidade e avaliação da qualidade ambiental. [acesso 20 maio 2009]. Disponível em: http://www.ctageo.com.br/ insercoes/TT79.pdf.

22. Crespilho MG, Souza PC. CD-Rom Portadores de deficiência e sua integração na sociedade. [acesso $10 \mathrm{abr}$. 2009]. Disponível em: http://200.169.53.89/download/CD\%20 congressos/2004/Sucesu/Posteres/ CD\%20Rom.PDF.

23. Carvalho EB, Silva PCM. Indicadores de acessibilidade no sistema de transporte coletivo: proposta de classificação em níveis de serviço. [dissertação]. [acesso 14 mar. 2010]. Disponível em: http://www. turismoadaptado.com.br/pdf/trabalhos_e_pesquisas/ acessibilidade_no_transporte_coletivo.pdf.

24. Cohen R. Cidade, corpo e deficiência: percursos e discursos possíveis na experiência urbana. [tese]. Rio de Janeiro: Universidade Federal do Rio de Janeiro; 2006.

25. Cal Auad J, Conceição MIG. Educação Especial Superior: o exemplo da Universidade de Brasília. Revista "Educação Especial". [online] 2009 [acesso 14 mar. 2010];22(34):213-24. Disponível em: http://www. ufsm.br/revistaeducacaoespecial.

26. Pletstch MD. Repensando a inclusão escolar de pessoas com deficiência mental: diretrizes políticas, currículo e práticas pedagógicas. [tese]. Rio de Janeiro: Universidade Estadual do Rio de Janeiro; 2009.
27. Miranda TG, Rosa DL. As múltiplas dimensões educativas da escola para o aluno com deficiência mental; 2006. [acesso 10 abr. 2009]. Disponível em: http://www.anped.org.br/reunioes/30ra/trabalhos/GT15-3587--Int.pdf.

28. Camargo ED, Nardi R. O emprego de linguagens acessíveis para alunos com deficiência visual em aulas de óptica. Rev Bras Ed Esp. 2008;14(3):405-26.

29. Elias MF, Monteiro LMC, Chaves CR. Acessibilidade a benefícios legais disponíveis no Rio de Janeiro para portadores de deficiência física. Associação Brasileira de Pós-Graduação em Saúde Coletiva; 2008. [acesso 26 maio 2010]. Disponível em: http://redalyc. uaemex.mx/redalyc/pdf/630/63013327.pdf.

30. Tafner MA, Fisher J. Paralisia Cerebral e aprendizagem: um estudo de caso inserido no ensino regular. Instituto Catarinense de Pós-Graduação. [acesso 30 fev. 2010]. Disponível em: www.icpg.com.br.

31. Lins LN, Souza FMC, Lins GCN. Fatores restritivos de pessoas deficientes na alocação de competências produtivas a conjuntos de tarefas organizacionais. Anais do 25ํㅡㄹ Encontro Nacional de Engenharia de Produção. Porto Alegre: Encontro Nacional de Engenharia de Produção; 2005.
Recebido: 03/08/2010

Received: 08/03/2010

Aprovado: 05/12/2011

Approved: 12/05/2011 